\title{
Bancos públicos e política anticíclica: uma análise exploratória com indicadores de alavancagem e liquidez da Caixa, Banco do Brasil e BNDES, no período de 2005 a 2014
}

State Owned Banks and anti-cyclical policy: an analysis of leverage and liquidity indicators from Caixa, Banco do Brazil and BNDES, in the period from 2005 to 2014

Daniel de Santana Vasconcelos,

daniel.s.vasconcelos@ufsc.br

Universidade Federal de Santa Catarina (UFSC)

Ana Paula Klaumann

anaklaumann96@gmail.com

Universidade Federal de Santa Catarina (UFSC)

Andrey Hamilka Ipiranga

andrey.ipiranga@yahoo.com

Universidade Federal de Santa Catarina (UFSC)

Resumo: O presente trabalho avalia o uso de bancos públicos na promoção de ações anticíclicas, no contexto da economia brasileira após a Crise de 2008, a partir de um referencial teórico pós-keynesiano. A utilização de bancos públicos na promoção do desenvolvimento e como parte do arsenal anticíclico de governos é bastante discutida nessa literatura. $\mathrm{O}$ trabalho analisa indicadores de alavancagem e liquidez da CEF, Banco do Brasil e BNDES no período de 2005 a 2014, levando em conta as condições financeiras desses bancos no período e sua atuação nas políticas anticíclicas de concessão de crédito no pós-crise de 2008 . O artigo conclui que os três bancos públicos brasileiros assumiram um perfil financeiro mais arriscado, refletindo sua participação no conjunto de políticas anticíclicas tomadas no momento em que o setor bancário privado entrava no processo de empoçamento de liquidez pós-crise.

Palavras-Chave: Bancos Públicos; Políticas Anticíclicas; Alavancagem Financeira; Liquidez Códigos JEL: E52; E61; E63.

Abstract: This paper evaluates the use of state owned banks in the promotion of countercyclical policy for the Brazilian economy after the 2008 Crisis, based on a post-keynesian theoretical framework. The use of state owned banks in promoting development and as part of the countercyclical arsenal of governments is much discussed in this literature. The paper analyzes the indicators of leverage and liquidity of CEF, Banco do Brazil and BNDES in the period from 2005 to 2014, taking into account the financial conditions of these banks in those years and their performance in countercyclical credit policies in the post-crisis of 2008. The article concludes that the three Brazilian state owned banks had taken a more risky financial profile, reflecting their participation in the set of countercyclical policies taken when the private banking sector entered the process of post-crisis flight to liquidity.

Keywords: State Owned Banks; Countercyclical Economic Policies; Financial Leverage; Liquidity JEL Codes: E52; E61; E63

Recebido em: 21-02-2018. Aceito em: 16-04-2018. 


\section{INTRODUÇÃO}

A necessidade de investimentos para a dinamização econômica das economias modernas passa, como coloca Gershenkron (1962), pela disponibilidade de fontes de financiamento que complementem os mecanismos de autofinanciamento. Já nos anos 1950 Gurley e Shaw (1955) enfatizavam as questões que ligam o desenvolvimento a um sistema financeiro nacional dinâmico e diversificado. Zysman (1983) coloca que não há modelo ideal de sistema financeiro, seja ele baseado em mercado de capitais ou no crédito bancário para o financiamento de longo prazo. Esses autores afirmam o papel fundamental dos canais de financiamento que possibilitam a mudança estrutural ligada ao desenvolvimento.

O papel de um sistema bancário no processo de desenvolvimento econômico é objeto de análise em diversos estudos sob a perspectiva teórica pós-keynesiana. No caso de países onde os sistemas financeiros não apresentam o grau de maturidade ou o perfil de aptidão para assumir os riscos de investimentos de longa maturação, parece claro que se faz necessário que tais deficiências sejam cobertas pela ação do Estado, em particular via bancos públicos. ${ }^{1}$ Carvalho (2005), Cintra (2005), Hermann (2009a; 2009b) avaliam especificamente o papel dos bancos públicos e sua relação com o desenvolvimento. Hermann (2010) e Carvalho $(2010)^{2}$ discutem os papeis do sistema financeiro e em especial dos bancos públicos na promoção de financiamento para o processo produtivo e o investimento com vistas ao desenvolvimento econômico brasileiro. Cordeiro (2015) também avalia a atuação dos bancos públicos brasileiros especialmente no pós-crise de 2008.

Para Hermann (2009a; 2010), várias são as características do desenvolvimento econômico que podem justificar a ação de bancos públicos no processo de financiamento, entre os quais destacam-se: i) a "incompletude" do mercado financeiro no que tange às necessidades de investimento, ligadas às elevadas incertezas associadas a investimentos de longo prazo em países em desenvolvimento; ii) a necessidade de autonomia financeira para a implementação de políticas de desenvolvimento, com os bancos públicos possuindo maior

\footnotetext{
${ }^{1}$ Daqui por diante, a expressão "bancos públicos" será utilizada sempre para referir-se a bancos que sejam puramente estatais ou de economia mista nos quais o governo detenha a maior parte das ações, constituindo-se, nesse sentido, em seu efetivo controlador societário. Na literatura em inglês, são o equivalente a state owned enterprises. Para fins do presente trabalho, portanto, a Caixa Econômica Federal (CEF), o Banco do Brasil (BB) e o Banco Nacional de Desenvolvimento Econômico e Social (BNDES) constituem bancos públicos, sem levar em conta maiores detalhes sobre sua forma de organização em termos legais.

${ }^{2}$ Esses dois textos encontram-se em IPEA (2010), respectivamente nos capítulos 9 e 10. Embora os respectivos capítulos não contenham as autorias, estas são informadas na abertura ("Agradecimentos") do referido volume. Doravante, vamos nos referir diretamente aos autores dos capítulos.
} 


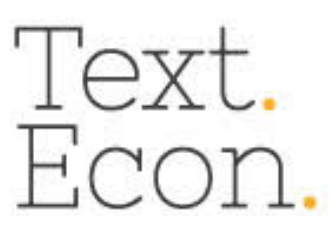

http://dx.doi.org/10.5007/2175-8085.2018v21n2p26

autonomia na alocação de recursos e no acesso a fontes de funding mais diversificadas que os seus respectivos governos controladores; e iii) a atuação anticíclica nos mercados de crédito, os bancos públicos podendo utilizar instrumentos que sigam na direção oposta àquela normalmente adotadas pelos bancos privados. ${ }^{3}$

A situação da economia mundial após a Crise Financeira ${ }^{4}$ de 2008 confirmou mais uma vez a previsão da teoria da preferência pela liquidez (Carvalho, 2015; Keynes, 1973), no fato de como as instituições bancárias privadas se retraem, num contexto de aumento da incerteza, buscando constituir reservas mais liquidas, mesmo que recebendo generosos volumes financeiros como socorro estatal, como no caso norte-americano (Vasconcelos, 2014; Kregel, 2008). Tais ações são marcadamente pró-cíclicas: enquanto os bancos elevam sua exposição a riscos e seu apetite por ganhos mais altos os leve a adotar posturas mais especulativas (no sentido de Minsky, 1975; 1982; 2008[1986]) durante fases expansivas dos ciclos econômicos, com o fim da expansão e a consequente reversão cíclica sua atitude típica é de retrair a concessão de crédito, buscando permanecer relativamente mais líquidos. Adicionalmente, o comportamento dessas instituições, nas crises mais recentes, especialmente a partir dos anos 1990, tem sido a de tentar buscar socorro oficial, como programas de resgate, que, como criticam alguns autores, são tipicamente instrumentos para socializar suas perdas (GOODHART, 2009; PAPADIMITRIOU E WRAY, 2010).

O fenômeno exibe fortemente o que Carvalho (2015) denomina em específico como a preferência pela liquidez dos bancos, e gera o que, no Brasil, em particular, se costuma chamar, na literatura, de “empoçamento da liquidez" (Oreiro e Basílio, 2008; de Paula, 2008). Bancos públicos acabam por se constituírem nas únicas instituições no setor financeiro que podem efetivamente ativar canais de crédito e destravar liquidez empoçada, em um momento em que o resto do sistema bancário se retrai, frente à incerteza. Nesse sentido, a atuação dos bancos públicos pode ser tipicamente anticíclica, se sua ação após uma crise for assim norteada pelo governo, enquanto seu controlador, com vistas a conter processos de aprofundamento recessivo como no pós-crise de 2008 (MENDONÇA E DEOS, 2010; CARVALHO, OLIVEIRA E TEPASSÊ, 2010).

A questão do financiamento do investimento público via bancos públicos suscita opiniões diversas, todavia, quando se foca nos aspectos da saúde financeira dessas

\footnotetext{
${ }^{3}$ Essa perspectiva é marcadamente oposta àquela apresentada, por exemplo, na coletânea de artigos em Pinheiro e Oliveira Filho (2007), cujo viés é mais pró-mercado.

${ }^{4}$ Doravante chamada simplesmente de "crise" ou crise de 2008.
} 
instituições. No caso brasileiro, em particular, a experiência de bancos públicos estaduais, cuja crise ficou patente após o fim do período de alta inflação até 1994, chamou a atenção para questões sobre solvência e liquidez das instituições que tenham o Estado como controlador ou principal acionista. ${ }^{5}$ Bancos são empresas com graus de alavancagem consideravelmente maiores que o restante das empresas das economias monetárias modernas. Em particular, suas atividades são desenvolvidas com descasamento de maturidades entre ativos e passivos, tornando-os sujeitos a situações de iliquidez ou, no limite, insolvência, típicas de agentes com finanças do tipo especulativas, na terminologia de Minsky (1982). Assim, uma avaliação da estabilidade das finanças de bancos públicos pode ser justificada tendo como objetivo a sua manutenção com instituições de fomento ao desenvolvimento e capazes de ações anticíclicas, sem a necessidade de socorros dos seus controladores no caso de insuficiência financeira (HERMANN, 2009a; 2010).

O presente artigo pretende fazer a avaliação de dois indicadores, o indicador de alavancagem financeira ${ }^{6}$ e o indicador de liquidez corrente ${ }^{7}$ dos três grandes bancos públicos ${ }^{8}$ brasileiros: a Caixa Econômica Federal (CEF), o Banco do Brasil (BB), e o Banco Nacional de Desenvolvimento Econômico e Social (BNDES), ${ }^{9}$ no período de 2005 a 2014, com base em seus balanços, com periodicidade trimestral para as duas primeiras, e semestral para a última. O período de análise compreende, portanto, tanto um cenário pré-crise (a partir da segunda metade do primeiro governo Lula, de 2003-2006), quanto os desdobramentos das finanças dessas instituições no pós-crise (segundo governo Lula, de 2007-2010) até o final do primeiro governo Rousseff (de 2011-2014). Os dados foram obtidos em balanços publicados na Revista Bancária Brasileira (RBB), edições de 2005 até 2014, ${ }^{10}$ a partir dos quais os dados foram compilados e calculados os indicadores.

\footnotetext{
${ }^{5}$ Há que se observar, todavia, que os bancos estaduais se tornaram instrumentos para outros propósitos (não necessariamente ligados ao desenvolvimento, mas, por exemplo, ao financiamento dos déficits dos estados) e/ou políticas locais/regionais descoordenadas com o governo federal, além de atuarem num ambiente regulatório e monetário muito específico, ainda no contexto da alta inflação dos anos 1970 até meados dos anos 1990.

${ }^{6}$ Sem entrar em detalhes de definições mais precisas, os termos indicador/índice serão utilizados de forma intercambiável no presente trabalho. O Indicador de Alavancagem Financeira (IAF) corresponde à razão entre o Ativo Total (AT) do banco e seu Patrimônio Líquido (PL): IAF = AT/PL.

${ }^{7} \mathrm{O}$ Indicador de Liquidez Corrente (ILC) corresponde à razão entre o Ativo Circulante (AC) e o Passivo Circulante $(\mathrm{PC})$ da instituição bancária: ILC $=\mathrm{AC} / \mathrm{PC}$.

8 "State owned banks", na literatura internacional.

9 A denominação geral de bancos públicos será clarificada ao longo do trabalho, quando se tratar de cada instituição e de suas especificidades em termos de organização (economia mista ou estatal puro).

${ }^{10}$ Revista Bancária Brasileira. Rio de Janeiro: Revista Bancária Brasileira (Mensal). Volumes consultados: v. 861; 862; 865b; 868; 871b; 874; 877b; 880; 883b; 886; 887; 889b; 892; 895b; 898; 901b; 904; 907b; 910; 913b; 916; 919b; 922; 925b; 928b; 931b; 934; 937b; 940; 943b; 946; 949b; 952; 955b; 958; 961b; 964; 967b; 970;
} 
O fenômeno da alavancagem diz respeito ao método pelo qual uma empresa se endivida, lançando mão de capital de terceiros com o intuito de aumentar a sua rentabilidade ou adquirir ativos. Quanto maior a alavancagem, maior a proporção de capital de terceiros em relação ao capital próprio da empresa. Já a análise da liquidez corrente oferece uma informação sintética sobre a capacidade de pagamento (isto é, de honrar compromissos financeiros) das instituições numa perspectiva de curto prazo. É o indicador típico da maior ou menor posse de margens de segurança em relação aos compromissos financeiros assumidos pelas unidades econômicas. ${ }^{11}$ A hipótese que norteia o artigo é que os bancos públicos objeto dessa análise podem revelar, através desses indicadores, por um lado, sua relativa fragilidade em termos de risco financeiro (no caso de alta alavancagem e baixos indicadores de liquidez) e, de outro lado, muito mais especificamente, sua possível atuação pró-cíclica (caso esses indicadores assumam valores que configurem busca por maior liquidez e menor alavancagem, quando o ciclo reverte) ou anticíclica (isto é, quando os indicadores seguem tendência oposta ao ciclo econômico).

As seções seguintes mostram os resultados dessa análise para a Caixa Econômica Federal (seção 2), Banco do Brasil (seção 3) e BNDES (seção 4). A seção 5 sintetiza a análise para os três bancos em simultâneo, e faz um exercício comparativo simples, tomando como referência os dados de dois grandes bancos privados que atuam no setor financeiro brasileiro. A comparação dos resultados dos três bancos públicos com os dois grandes bancos privados permite enxergar com mais clareza a natureza anticíclica da atuação dos primeiros e prócíclica dos segundos, no caso da economia brasileira no período estudado. Com base nessas análises, a seção 6 traz a conclusão do artigo.

\section{INDICADORES DA CAIXA ECONÔMICA FEDERAL}

A Caixa Econômica Federal (CEF) é uma empresa pública (um banco estatal, portanto) que exerce no Brasil a atividade típica de caixa econômica. ${ }^{12}$ A missão institucional

973b; 976; 979b; 982; 985b, compreendendo o período de abril de 2005 a janeiro de 2015. Os dados para o BNDES foram obtidos diretamente no site da instituição.

${ }^{11}$ Vale lembrar que tanto a alavancagem quanto a constituição de margens de segurança são mecanismos típicos de comprometimento (e relativa proteção) dos passivos das unidades econômicas, com vistas a adquirir ativos. Ambos estão ligados à condição de solvência/insolvência e de liquidez/iliquidez relativa das instituições em relação aos compromissos financeiros assumidos, representados pelo lado do Passivo em seus balanços. Esse processo é tratado em Minsky (1975; 1986). Ver também Kregel (2008).

${ }_{12}$ As caixas econômicas são instituições voltadas a recolher e movimentar poupança popular, e no caso específico da CEF, a receber depósitos de diversas rubricas referentes a pagamentos de direitos trabalhistas. A 
da CEF, segundo suas informações públicas, é de "[a]tuar na promoção da cidadania e do desenvolvimento sustentável do País, como instituição financeira, agente de políticas públicas e parceira estratégica do Estado brasileiro." 13

A CEF é vinculada ao Ministério da Fazenda, tendo no Governo Brasileiro seu único controlador. Nesse aspecto, portanto, a CEF, embora goze de fontes de funding próprias asseguradas em lei, além de fontes de recursos das suas operações bancárias típicas, tem no Tesouro Nacional a fonte final de aportes de capital, seja para fins de observância de mínimos regulatórios (como no ajuste a regras de regulação bancária como as regras da Basileia), seja para cobrir eventuais deficiências de capital, no caso de resultados econômicos negativos de suas atividades. Portanto, é de especial interesse uma observação de seus níveis de endividamento e liquidez.

Os níveis de alavancagem da CEF são normalmente elevados. Séries de dados em outros trabalhos (Hermann 2010) mostram um patamar de alavancagem elevado desde os anos 1990. No entanto, como parte das políticas de contenção dos efeitos da Crise Financeira de 2008 sobre a economia brasileira, o governo federal, naquela ocasião, fez amplo uso dos bancos públicos como provedores de crédito de natureza anticíclico. Os níveis de alavancagem da CEF elevaram-se patamares que flutuavam entre 20 a 25 vezes o PL para níveis superiores a 25 vezes a partir de 2009 (vide Gráfico 1).

Pode-se creditar à continuidade de políticas de crédito ao consumo, mantidas nos anos pós-crise como medidas anticíclicas por parte do governo de então, parte da origem dessa alavancagem mais elevada. Nos anos pós-crise, entre outras ações de política anticíclica, vale lembrar o episódio em que o Banco Central ensaiou uma redução das taxas de juros, em 2012, tendo o governo utilizado os bancos públicos (CEF e BB) como

CEF é responsável pela carteira de crédito imobiliário no Brasil, e pelas loterias federais (ABRÃO, 2009). A origem das caixas econômicas é paralela à dos bancos, tendo sua forma original nos chamados "montes de socorro", um estágio primário de captação de recursos líquidos para camadas muito pobres da população (no caso da cidade de Veneza, na Itália medieval) ou das saving and loans instituions, na Inglaterra. As primeiras caixas econômicas diferiam dos bancos comerciais primeiramente por oferecer às populações mais carentes empréstimos com juros menores, pelo cunho educativo de seus programas, pela não distribuição de lucros e dividendos aos seus controladores e pelo investimento desses lucros no reforço dos fundos de reserva, bem como o financiamento de algumas atividades produtivas simples (SILVA, 2004). Silva argumenta que em geral, em qualquer lugar em que estejam inseridas, as caixas econômicas recebem assistência estatal. A CEF nasceu, de fato, em 1861, como Caixa Econômica da Corte, seguida em 1874 pelas caixas econômicas das províncias (22, à época,) transformadas em 1889 em Caixas Econômicas Federais. Em 1970 essas 22 instituições foram unificadas em uma só: a Caixa Econômica Federal (CEF).

${ }^{13}$ Dentre as suas principais funções está a de assegurar certos benefícios aos trabalhadores, como o Fundo de Garantia do Tempo de Serviço (FGTS) e o pagamento do Seguro-Desemprego, o financiamento de alguns programas sociais, como o Minha Casa Minha Vida e o Bolsa Família, efetuar cadastros de identificação social, como o Cadastro de Pessoa Física (CPF), além de ser o detentor do monopólio das Loterias Federais desde 1961 (ABRÃO, 2009, e informações no site da instituição). 
instrumentos para forçar a queda nas taxas de juros ao consumidor, contrapondo-se ao comportamento dos bancos privados. ${ }^{14}$ Os bancos públicos também foram utilizados para adquirir participação em outras instituições, destacando-se as aquisições da Nossa Caixa (2008), do Banco da Patagônia (2010) e do EuroBank (2011) pelo BB, e a aquisição de participação da CEF de 35,5\% do Banco Pan Americano, por R\$ 740 milhões, em 2009. ${ }^{15}$

Como resultado dessas políticas anticíclicas, a CEF assumiu uma postura financeira mais arriscada após a crise de 2008, chegando já no terceiro trimestre de 2009 a uma alavancagem superior a 27 vezes s eu capital. ${ }^{16}$ No período subsequente a alavancagem da CEF continuou em patamares bastante altos, chegando inclusive a níveis superiores aos da Crise, alcançando o ponto máximo de 32,3 no terceiro trimestre de 2013. O nível de alavancagem só veio a se contrair a partir de 2014, chegando ao mínimo de 15,82 no terceiro trimestre de 2014.

Gráfico 1 - Alavancagem da CEF entre 2005 e 2014

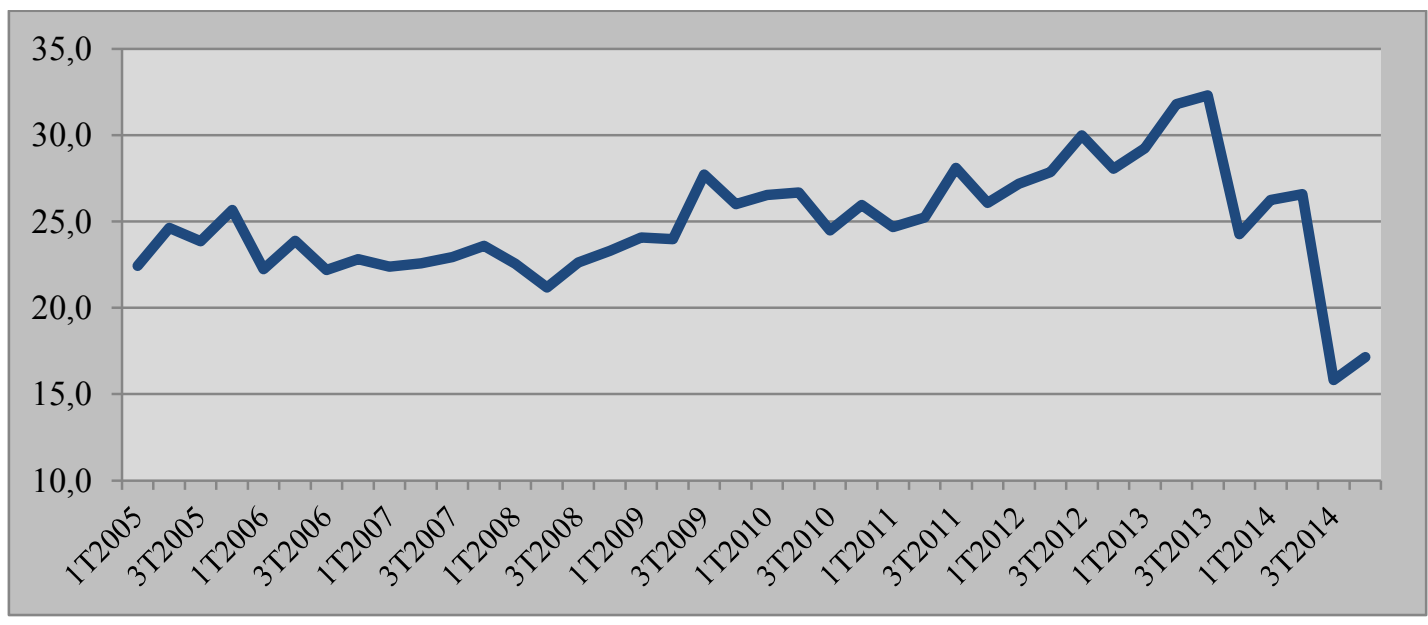

Fonte: Elaborado pelos autores a partir da Revista Bancária Brasileira.

\footnotetext{
${ }^{14}$ Ver, por exemplo, o noticiário da época (a título de informação: http://g1.globo.com/economia/seudinheiro/noticia/2012/04/apos-bb-e-caixa-bancos-privados-avaliam-reducao-de-taxas-de-juros.html, Acesso em julho de 2017).

${ }^{15}$ Vide, por exemplo: http://economia.estadao.com.br/noticias/geral,compra-da-nossa-caixa-fortalece-banco-dobrasil-diz-mantega,280985, Acesso em julho de 2017; https://agenciabrasil.jusbrasil.com.br/noticias/2024595/caixa-economica-compra-35-5-do-banco-panamericano-por-cerca-de-r740-milhoes, Acesso em julho de 2017.

${ }^{16}$ Vale lembrar que o banco Lehman Brothers, nos Estados Unidos, cuja quebra em setembro de 2008 foi praticamente o elemento catalisador da crise financeira a partir daquele ano, veio à bancarrota com uma alavancagem em torno de 30 a 40 vezes seu capital próprio (Bair, 2012; Admati e Hellwig, 2013; Blinder, 2013; King, 2016).
} 


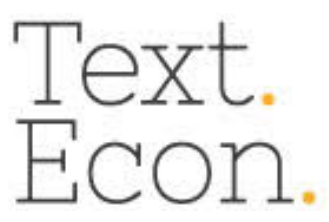

http://dx.doi.org/10.5007/2175-8085.2018v21n2p26

Outro índice analisado para avaliar a posição da CEF no período é o de indicador liquidez corrente (ILC). Este constitui-se num indicador de capacidade de capital do banco para a quitação de dívidas de curto prazo. Um indicador menor que um revela uma posição ilíquida, o que mostraria que a instituição não possui recursos suficientes para honrar seus compromissos de curto prazo. ${ }^{17}$

O Gráfico 2 mostra os resultados do ILC para o banco, em base trimestral, no período deste estudo. Em todo o período analisado a CEF exibe indicadores inferiores à unidade, configurando uma posição de relativa iliquidez, em particular nos anos de 2008 e 2009. O ILC melhora nos períodos seguintes, chegando ao valor de 0,944 no segundo trimestre de 2012 e 0,927 no primeiro trimestre de 2013. Em que pese essa melhora relativa, a situação geral da instituição não uma situação tal que seu ILC ultrapasse a unidade.

A CEF exibiu, portanto, uma condição de liquidez em posição relativamente arriscada, em especial nos anos mais agudos da crise financeira internacional, levando possivelmente ao questionamento sobre como a CEF não entrou em processo mais grave de iliquidez e mesmo insolvência, dados os indicadores, em geral, ruins. Aqui entra seu papel como parte de um arcabouço institucional com vistas ao desenvolvimento econômico do país, e ainda como parte do arsenal anticíclico do governo brasileiro. A sua posição como banco estatal certamente lhe permite maiores margens de manobra, não obstante a sua posição financeira ter se tornado, nesse período, seguindo o referencial minskyano de posturas financeiras, fortemente especulativa.

\footnotetext{
${ }^{17}$ No contexto das novas regras de Basileia, ou Basileia 3, atualmente em implantação, um tratamento especial vem sendo dado aos índices de liquidez para prazos curtos, definido como Razão de Cobertura de Liquidez, que compreende a manutenção de ativos de alta liquidez para quitação de compromissos de até 30 dias (CGFS, 2011; Vasconcelos, 2014)
} 


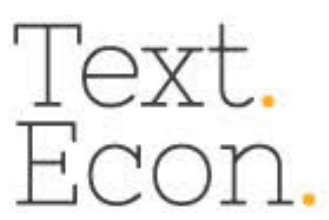

Gráfico 2 - Indicador de Liquidez Corrente da CEF entre 2005 e 2014

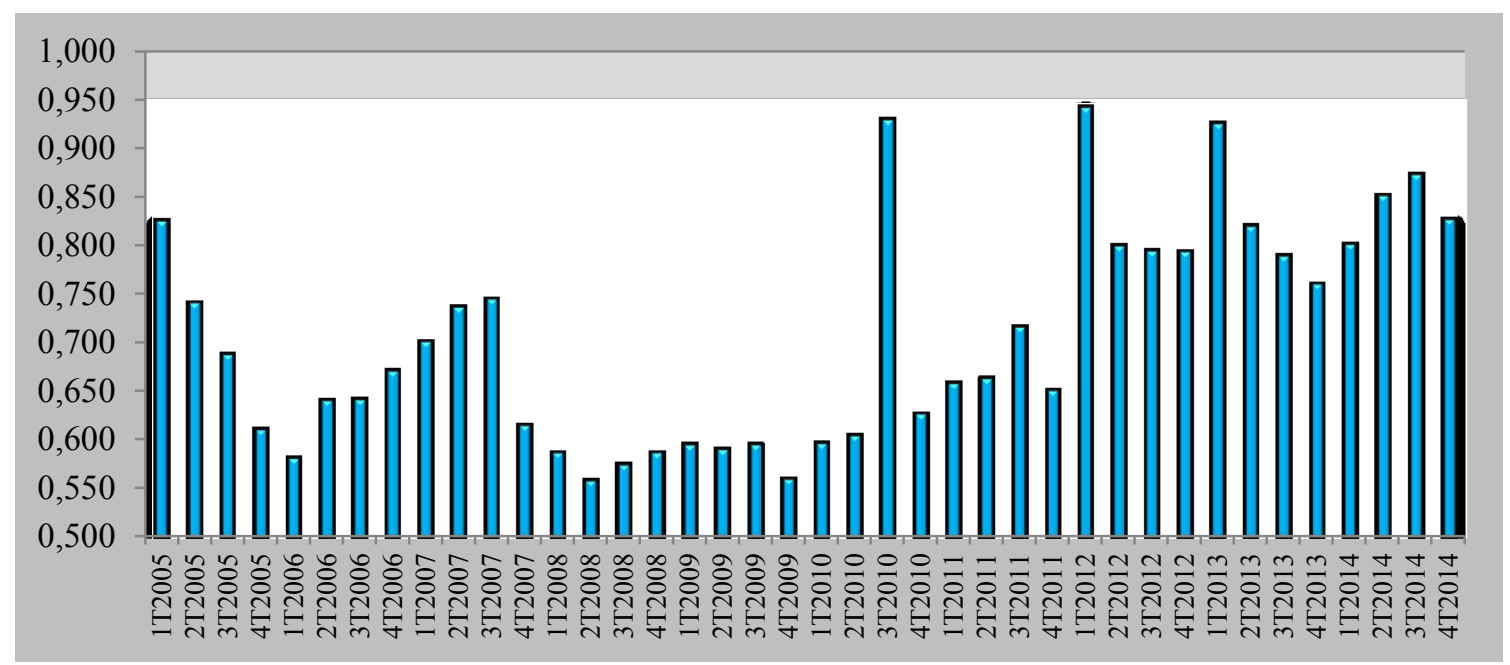

Fonte: Elaborado pelos autores a partir da Revista Bancária Brasileira.

Uma das causas para a sustentação financeira da instituição foi o processo de capitalização pela qual ela passou em 2001, chamado de Programa de Fortalecimento das Instituições Financeiras Federais, do governo federal, que, segundo nota oficial, objetivava a adequação patrimonial das instituições públicas às regras de Basileia I, então em início de implantação (MINISTÉRIO DA FAZENDA, 2001; ARAÚJO E CINTRA, 2011). Esse processo resultou em uma capitalização de $\mathrm{R} \$ 9,3$ bilhões da $\mathrm{CEF}$, à época, com recursos do Tesouro Nacional, reestruturando a instituição e submetendo-a as mesmas condições dos bancos privados.

Como resultado dessa reestruturação, quando da chegada da crise e de seus posteriores desdobramentos no mundo e no Brasil, a instituição estava relativamente mais forte. Seus indicadores pioraram significativamente no após crise, em face das ações anticíclicas nas quais a instituição foi empregada. O governo, como já foi dito, utilizou amplamente os seus bancos públicos no período pós-crise, elevando a participação dos mesmos na concessão total de crédito no país. ${ }^{18}$

\section{INDICADORES DO BANCO DO BRASIL}

Criado ainda nos tempos do Brasil Colonial, quando da chegada da Corte Portuguesa no Rio de Janeiro, em 1808, o Banco do Brasil é um dos grandes bancos nacionais, com a

\footnotetext{
${ }^{18}$ Vide Cordeiro (2015).
} 
característica adicional de constituir-se, juntamente com a CEF, nos dois bancos com maior capilaridade no país, isto é, com mais agências distribuídas na maior parte do território nacional, incluindo municípios menores e regiões economicamente mais pobres. ${ }^{19} \mathrm{O}$ Banco do Brasil é um banco público de capital aberto (empresa de economia mista), com funções típicas de um banco comercial de capital aberto, mas exercendo paralelamente atividades de interesse do governo, como ser o banco de movimentação financeira do governo federal (o BB é o banco da Conta Única do Tesouro Nacional), bem como dos poderes legislativo e judiciário na esfera federal, e ser o banco que operacionaliza o crédito rural (ABRÃO, 2009).

A composição acionária do Banco do Brasil é dividida entre a União Federal, com algo em torno de $54 \%$ das ações, e um free float de algo em torno de $42 \%$ do capital (dos quais o capital estrangeiro chega a patamares entre $19 \%$ e $20 \%$ da participação), o restante constituindo-se em ações em tesouraria (valor em geral abaixo de $3 \%$ do capital). ${ }^{20}$ A União, sendo a principal acionista, confere obviamente maior poder decisório ao governo na gestão do banco.

No que diz respeito às condições imediatamente pré e pós-crise financeira, a situação do BB reflete a sua condição peculiar de empresa de economia mista. Devido ao fato de o Banco do Brasil ter capital aberto, ele foi afetado (tanto pela crise, quanto pelas políticas adotadas após a mesma) de maneira diferente que os outros bancos. Embora à época o banco mostrasse bons fundamentos em termos de balanço, as ações do banco negociadas em bolsa foram as mais prejudicadas, dentre as ações de bancos listadas na Bovespa (PASSOS, 2010).

Em termos de níveis de alavancagem, o banco preservou um patamar oscilando em torno de 14 a 15 vezes o Patrimônio Líquido. Os dados permitem ver com certa clareza o comportamento anticíclico do banco, refletido no aumento de sua alavancagem notadamente nos períodos pós-crise (2009 e 2010) e no agravamento da situação econômica do país, a partir de 2013. O BB é a maior instituição provedora de crédito rural no país, além de conceder crédito também para a infraestrutura e a indústria (aquisição de máquinas e equipamentos). Esse último, em particular, cresceu de forma expressiva nos anos da crise (ARAÚJO e CINTRA, 2011). Ainda assim, os níveis de alavancagem foram bem menos acentuados que os da CEF, vistos anteriormente. Durante todo o período de análise o maior

\footnotetext{
${ }^{19} \mathrm{O}$ site oficial do BB informa a existência de cerca de 4 mil agências e mais de 40 mil caixas eletrônicos no país, e presença em mais de 50 localidades no exterior. Já a CEF, além da rede de agências, conta ainda com a rede de casas lotéricas, que fazem serviços de correspondente bancário integrados à rede do banco.

${ }^{20}$ Os valores dados no trabalho são aproximados, e refletem o fato de que flutuações diárias nos preços das ações modificam sensivelmente esses valores ao longo do tempo, resguardada a participação majoritária na União no banco.
} 


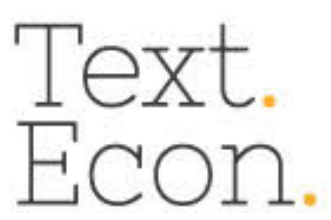

http://dx.doi.org/10.5007/2175-8085.2018v21n2p26

valor encontrado foi de 19,225 vezes, no primeiro trimestre de 2010. Notadamente no período pré-crise e desde fins de 2010 até o início de 2012, os níveis de alavancagem foram consistentemente mais moderados. É visível que o banco acentuou sua alavancagem como parte do arsenal anticíclico adotado pelo governo tanto no pós-2008 quanto na piora das condições econômicas do país, verificadas de 2013 em diante.

Gráfico 3 - Alavancagem do BB entre 2005 e 2014

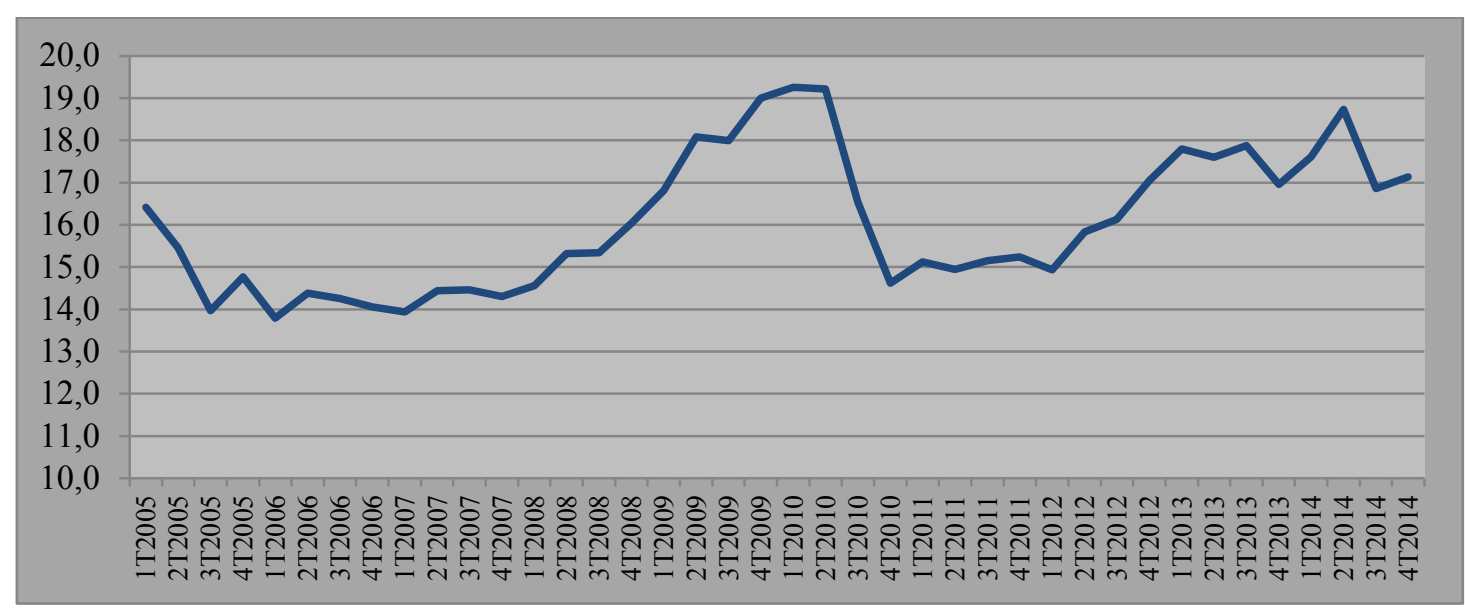

Fonte: Elaborado pelos autores a partir da Revista Bancária Brasileira.

A análise da liquidez corrente do BB também revela algo curioso: o ILC do banco cresceu ao longo da sua atuação anticíclica. Houve um esforço a partir da crise para elevar os patamares de liquidez do banco, com o pico de 0,939 no primeiro trimestre de 2012. Observase que os níveis voltaram a cair a partir de então, chegando ao final do período de análise ao patamar de 0,773 . 
Gráfico 4 - Indicador de Liquidez Corrente do BB entre 2005 e 2014

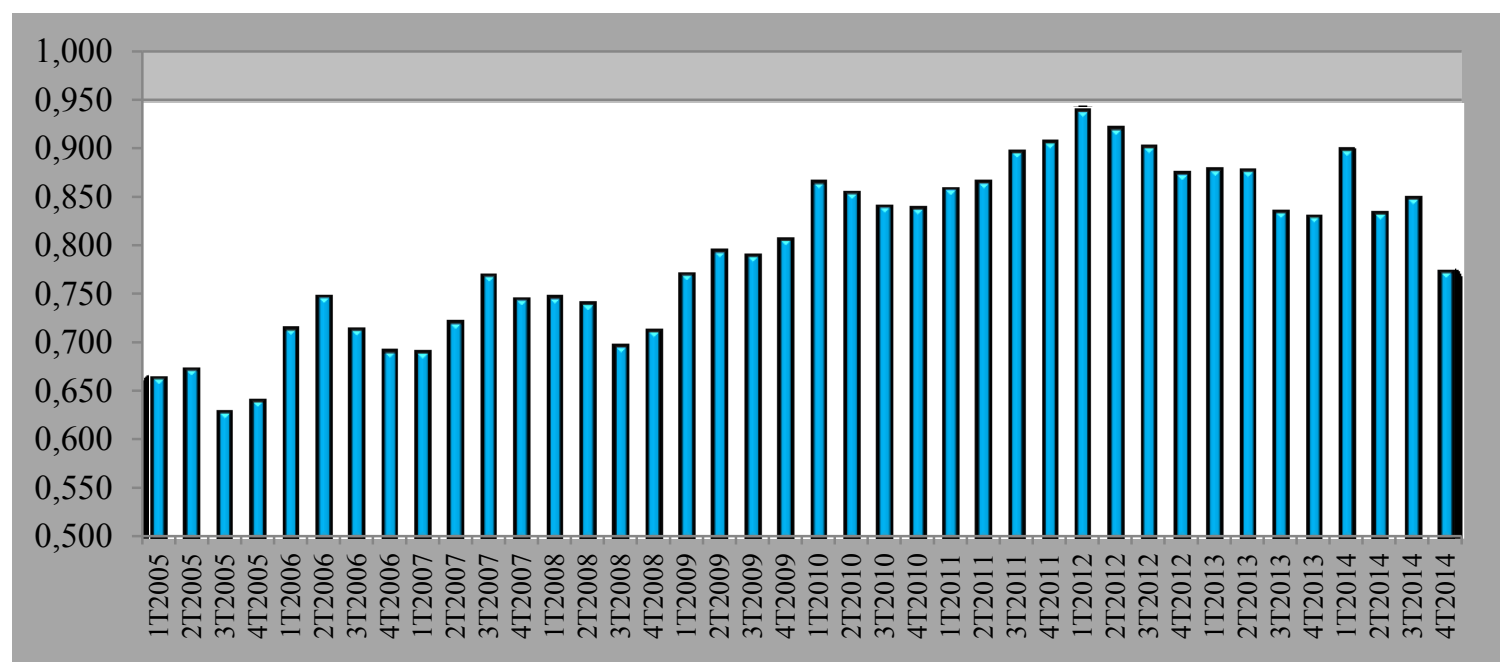

Fonte: Elaborado pelos autores a partir da Revista Bancária Brasileira.

Passos (2010) argumenta que a incerteza acerca da condição dos bancos privados levou muitos brasileiros a se refugiarem nos bancos públicos (CEF e BB), migrando suas aplicações e operações para essas instituições. Vale lembrar que a política de redução de juros em 2012 foi também responsável por uma ampliação do crédito dos bancos públicos, que ganharam clientes, tanto pelo fator de concorrer com preços mais baixos para diversas modalidades de concessão de crédito, quanto pela ampliação que conseguiram por meio da política de aquisições promovida à época ${ }^{21}$ (ARAÚJO e CINTRA, 2011). A política de aquisições e de ampliação do crédito fez crescer significativamente a sua participação do BB no Sistema Financeiro Nacional, consolidando-o como o maior banco brasileiro.

\section{INDICADORES DO BNDES}

A criação do BNDES remonta o período da história brasileira marcado pelo auge do chamado "desenvolvimentismo", o qual foi a "ideologia econômica de sustentação do projeto de industrialização integral, considerada como forma de superar o atraso e a pobreza brasileiros" (BIELSCHOWSKY, 2000, p. 77). Com o projeto industrializante sendo iniciado no governo Vargas, enxergou-se e a necessidade da construção de um arcabouço institucional

\footnotetext{
${ }^{21}$ Além desses aspectos, no mesmo período o BB ingressou no mercado de crédito imobiliário e de veículos, também como resultado da política de aquisição acionária de outros bancos. O primeiro deles foi, em 2008, o Banco Estadual de Santa Catarina (BESC), o Banco Estadual do Piauí (2008), seguido pela aquisição de 71,25\% do Banco Nossa Caixa, do Estado de São Paulo (também em 2008) e de 50\% do Banco Votorantim em 2009. Em 2010 o BB adquiriu controle ainda do Banco Popular do Brasil e de parte do Banco da Patagônia (PASSOS, 2010).
} 


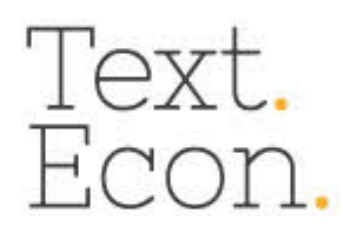

http://dx.doi.org/10.5007/2175-8085.2018v21n2p26

inserido na lógica desenvolvimentista, incluindo aí um banco público de investimento, alinhado com as ideias financiamento da industrialização e do avanço tecnológico (DRAIBE, 1985, apud REDIVO, 2012). Dentro desse marco institucional, a criação do BNDES em 1952 respondeu à necessidade de preenchimento da lacuna do sistema financeiro nacional no que diz respeito às condições de financiamento de longo prazo, fundamental para a viabilização dos projetos de infraestrutura e de indústrias de base no país. ${ }^{22}$

A estrutura financeira do BNDES revela-se mais estável do que a dos demais bancos públicos, por diversas razões. Em especial, destaca-se a estabilidade da principal fonte de funding da instituição (o FAT - Fundo de Amparo ao Trabalhador), e a natureza de sua atividade como banco de investimentos. A atuação do BNDES se dá, entre outras atividades, na ampliação das linhas de financiamento às exportações, redução dos custos de financiamento, ampliação da oferta de capital de giro, ampliação do nível de participação no investimento de capital das empresas, estímulos à aquisição e produção de bens de capital, além de garantir a capacidade de investimentos dos estados (COUTINHO, 2011; COUTO; TRINTIM, 2012). Os contratos de financiamento do banco tendem a ser mais estáveis, a análise de crédito é mais específica, e os compromissos assumidos, incluindo a participação acionária em empresas que recebam financiamento, geram um compromisso de maior estabilidade entre o banco e seus financiados, resultando em baixa inadimplência. Essas características se revelam nos indicadores analisados para o banco, no âmbito desse trabalho. $^{23}$

Analisando-se os níveis de alavancagem do BNDES observa-se uma tendência ascendente a partir do segundo semestre de 2008, culminando em um nível de alavancagem de 15,448 no segundo semestre de 2010. Essa grandeza não chega a constituir um número significativo, se comparado aos níveis de alavancagem de CEF e BB, no mesmo período. No entanto, o valor se destaca quando observado em relação à trajetória anterior ao ano de 2008 , quando a alavancagem vinha se reduzindo. Os níveis de alavancagem do BNDES estão estreitamente relacionados com a crise de 2008 e à atuação do banco na promoção de políticas anticíclicas, sobretudo no que diz respeito à provisão de crédito para o setor industrial, o qual, apesar de perder espaço para o BB, teve um aumento de 53\% entre agosto de 2008 e agosto de

\footnotetext{
${ }^{22} \mathrm{O}$ funding do BNDES vem da administração do FAT (Fundo de Amparo ao Trabalhador).

${ }^{23}$ A análise do BNDES apresenta uma diferença em relação aos outros dois bancos tratados no presente trabalho. Enquanto na CEF e BB a avaliação se deu em bases trimestrais, os dados obtidos para o BNDES foram em periodicidade semestral.
} 
2009, em termos reais (ARAÚJO e CINTRA, 2011). ${ }^{24}$ Após uma abrupta redução em 2010, os níveis de alavancagem voltaram a se elevar entre 2011 e 2012, com leve redução após período.

Gráfico 5 - Alavancagem do BNDES entre 2005 e 2014

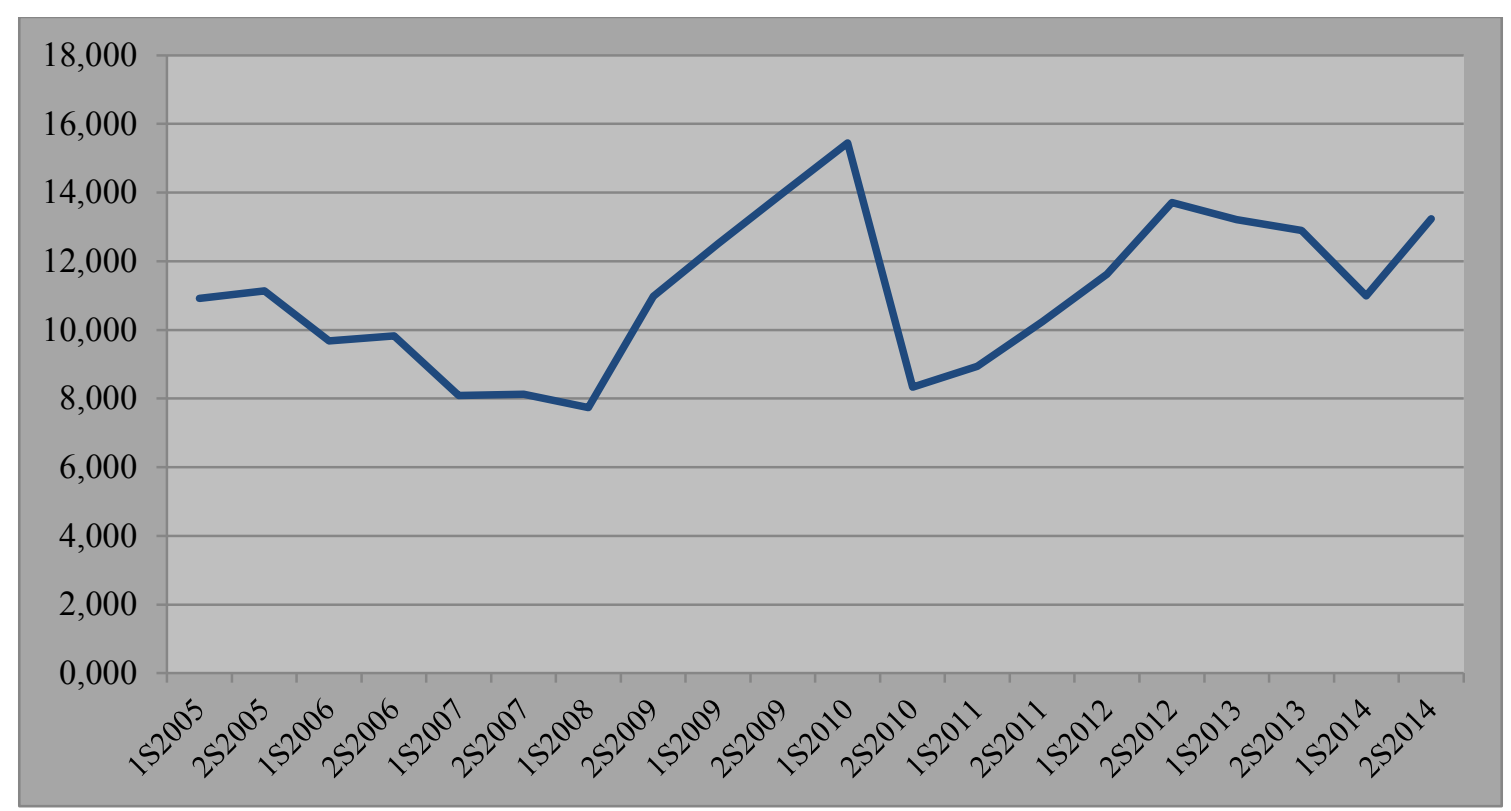

Fonte: Elaborado pelos autores a partir de dados do BNDES.

Em relação aos níveis de liquidez corrente o BNDES não apresentou valores críticos no período estudado. Há uma clara tendência de queda no ILC no período de aprofundamento da crise, com a instituição apresentando um indicador de liquidez corrente de 2,154 no segundo semestre de 2009, sendo esse o menor valor no período estudado. Observa-se que a partir daí os níveis de liquidez passaram a apresentar grandes variações, embora normalmente operando em patamares bem elevados. Mesmo no período compreendido entre o segundo semestre de 2012 e os dois semestres de 2013, quando houve redução do ILC, este ainda foi mantido num patamar acima de 3,0 .

\footnotetext{
${ }^{24}$ Vale destacar ainda a expansão de crédito implementada pelo BNDES entre setembro e dezembro de 2008, justamente na eclosão da crise financeira. Segundo Couto e Trintim (2012) o BNDES sozinho respondeu por 32 pontos percentuais dos $68 \%$ de participação dos bancos públicos na oferta de crédito global da economia brasileira naquele período.
} 
Gráfico 6 - Liquidez Corrente do BNDES entre 2005 e 2014

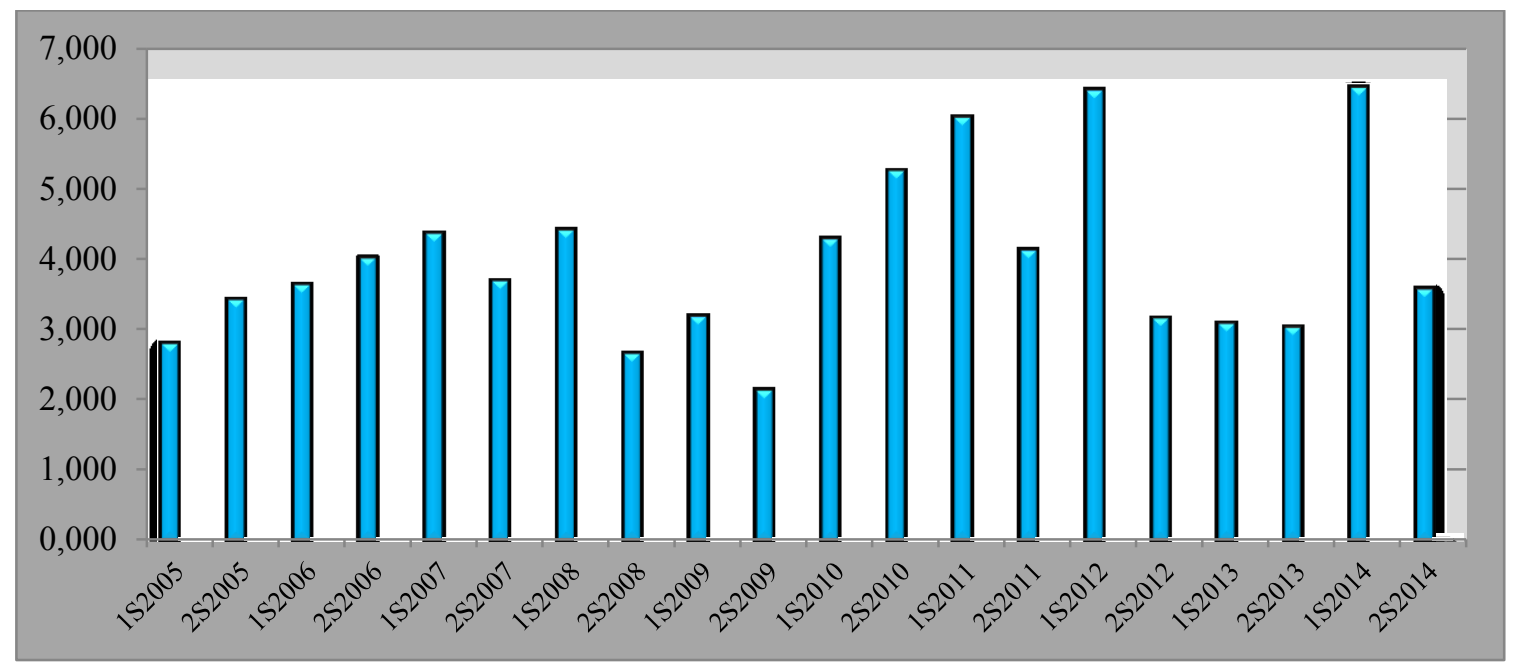

Fonte: Elaborado pelos autores a partir do BNDES.

\section{SÍNTESE COMPARATIVA dOS BANCOS PÚBLICOS E BREVE PARALELO COM ALGUNS BANCOS PRIVADOS}

Como exercício complementar à presente análise, plotamos graficamente os indicadores de alavancagem e de liquidez corrente dos três bancos públicos tratados na análise precedente. Na tentativa ainda de lançar luz sobre essa análise, fizemos a comparação dos mesmos indicadores tomando como referência dados de dois bancos privados com expressiva participação de mercado, no setor financeiro brasileiro. ${ }^{25}$ Inicialmente, comparamos somente os resultados dos bancos públicos entre si. ${ }^{26}$

O Gráfico 7 mostra, de forma simultânea, a evolução dos níveis de alavancagem para os três bancos públicos no período compreendido entre 2005 e 2014. Fica nítida a trajetória ascendente para os três bancos a partir do $2^{\circ}$ trimestre de 2008. No entanto, BB e BNDES parecem ter retornado a uma trajetória mais consistente com os níveis de alavancagem précrise, não obstante a relativa elevação, embora mais moderada, após 2011. A CEF, no entanto,

\footnotetext{
${ }^{25}$ OS bancos privados cujos dados são utilizados para comparação são o Bradesco e o Santander. Era desejo dos autores utilizar também dados dos bancos Itaú e Unibanco, mas o processo de fusão entre as duas instituições, iniciado em novembro de 2008, impossibilitou a análise, na forma como foi possível ser conduzida nas outras duas instituições privadas.

${ }^{26}$ A comparação direta entre as instituições pode ser questionada: a CEF é uma caixa econômica, o BB é tipicamente um banco comercial, e o BNDES um banco de investimento. Os autores estão cientes disso. No entanto, como o objetivo do trabalho é avaliar sinteticamente os resultados das ações conjuntas de natureza anticíclica desses bancos, a comparação dos indicadores de alavancagem e ILC, somente, não constitui um exercício espúrio. Não se está comparando as instituições entre si, mas apenas verificando em que grau elas foram relativamente mais um menos arriscadas em suas estratégias de expansão durante o período coberto pela presente análise.
} 


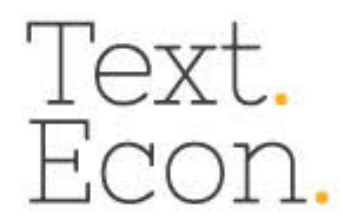

http://dx.doi.org/10.5007/2175-8085.2018v21n2p26

esteve sempre em posição muito mais arriscada, com níveis de alavancagem muito descolados dos outros dois bancos, e mantenho-os elevados e em trajetória crescente até 2013.

Gráfico 7 - Alavancagem Caixa, BB e BNDES entre 2005 e 2014

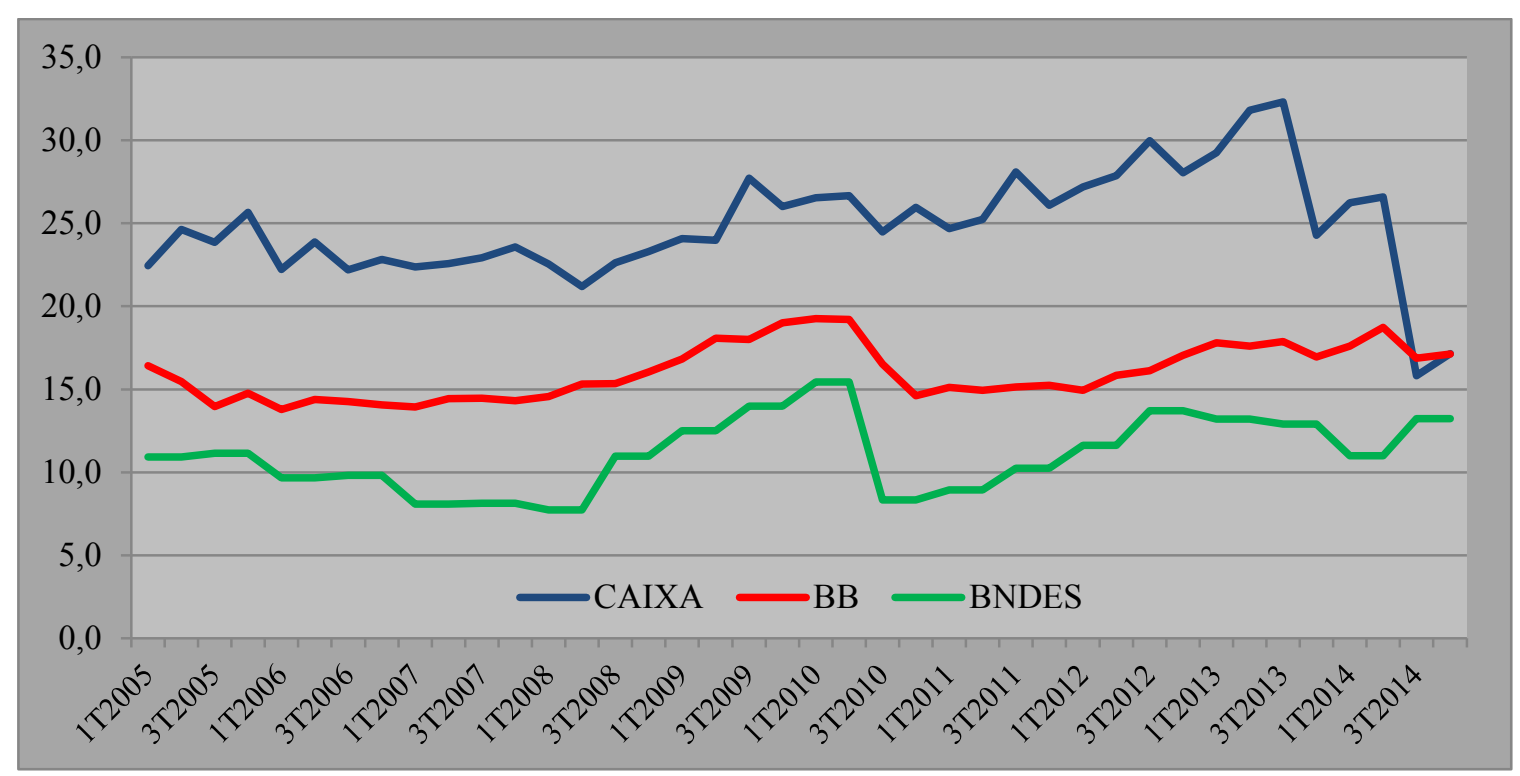

Fonte: Elaborado pelos autores a partir da Revista Bancária Brasileira e do BNDES.

O Gráfico 8 realiza o mesmo exercício comparativo, leva em conta os indicadores de liquidez das três instituições. Como observado anteriormente, apenas o BNDES manteve margens mais seguras e estáveis ao longo do período. As outras duas instituições financeiras apresentaram ILC baixo ao longo de todo o período, com piora nos períodos pós-crise. 


\section{Text.
Econ}

Gráfico 8 - Indicadores de Liquidez Corrente - CEF, BB e BNDES entre 2005 e 2014

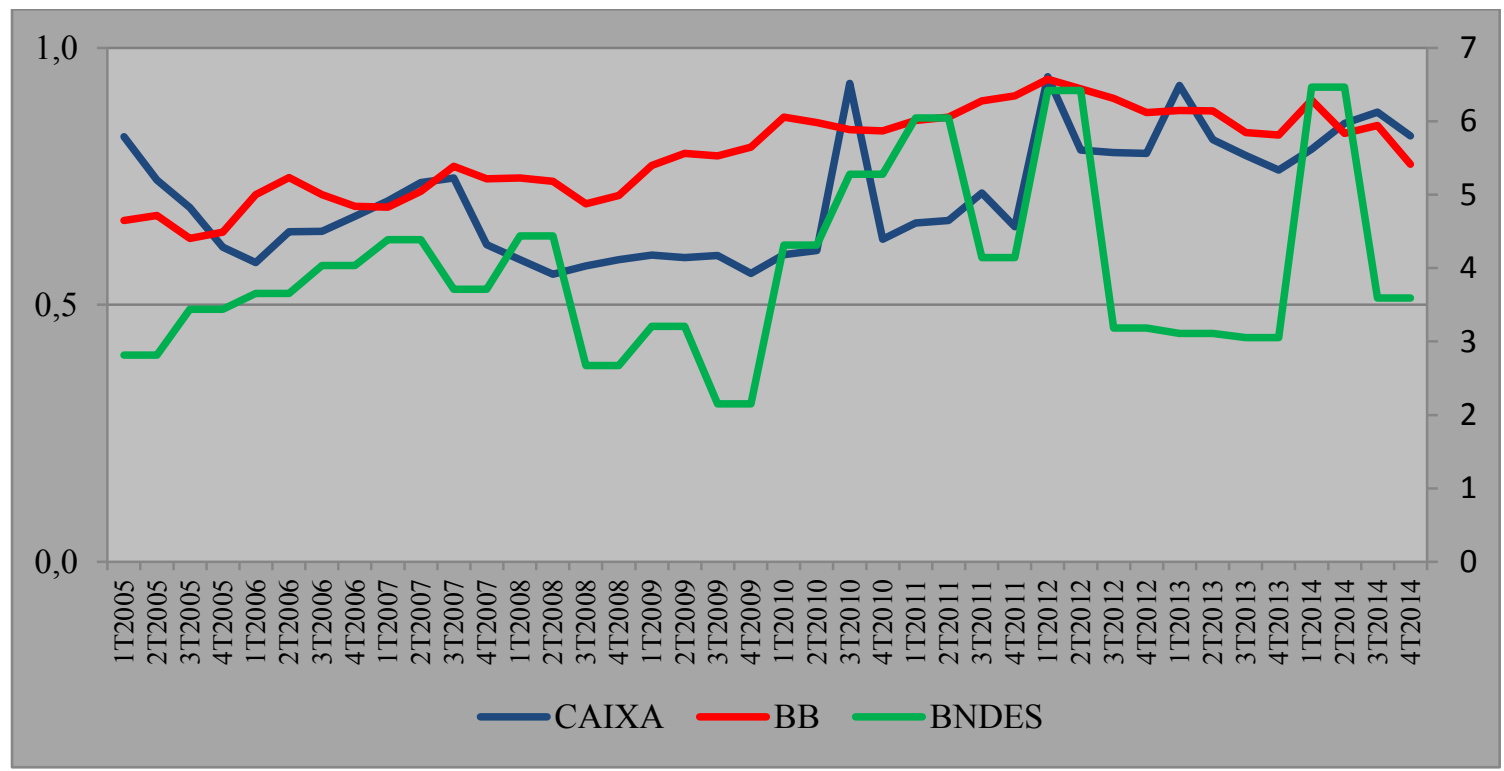

Fonte: Elaborado pelos autores a partir da Revista Bancária Brasileira e do BNDES.

OBS.: ILC do BNDES no eixo à direita.

Fazendo-se uma comparação dos indicadores dos três bancos públicos com duas das principais instituições financeiras privadas presentes no país, o Bradesco e o Santander, é possível observar o contraste entre a evolução dos níveis de alavancagem no contexto de crise entre instituições financeiras públicas e privadas, no contexto brasileiro. Enquanto os bancos públicos revelaram trajetória ascendente, justamente no período de crise econômica, os dois bancos privados tomados para comparação exibiram trajetória relativamente mais estável (Bradesco) ou descendente (no caso do Santander, cuja alavancagem, após oscilações nos anos pré-crise, caíram a níveis comparativamente baixos no imediato período da crise. Os bancos públicos tiveram maior exposição justamente no auge da crise, enquanto bancos privados reduziam o crédito, num clara atitude pró-cíclica.

Já no que diz respeito à liquidez corrente, a comparação do ILC entre as diferentes instituições revela uma diferença crucial entre as condições financeiras dos bancos públicos da presente análise (excluindo-se o BNDES) em relação aos dois bancos privados tomados como comparação. O Gráfico 10 mostra que o ILC (e, portanto, a condição de liquidez e, e última análise, de solvência) dos bancos privados esteve sempre acima do dos bancos públicos no período analisado. Em particular, no contexto de crise, ainda que a trajetória do ILC das duas instituições privadas tenha sido descendente, esse indicador permaneceu em geral acima de 1,0 nos anos imediatamente após a crise financeira, reduzindo-se a partir de 


\section{Text. Econ.}

2011, mas ainda estando em patamares superiores aos da CEF e BB. Novamente, vale destacar a Caixa Econômica, que passou o período da crise com sua capacidade de liquidez relativamente mais prejudicada.

Gráfico 9 - Alavancagem do BB, Caixa, Bradesco e Santander entre 2005 e 2014

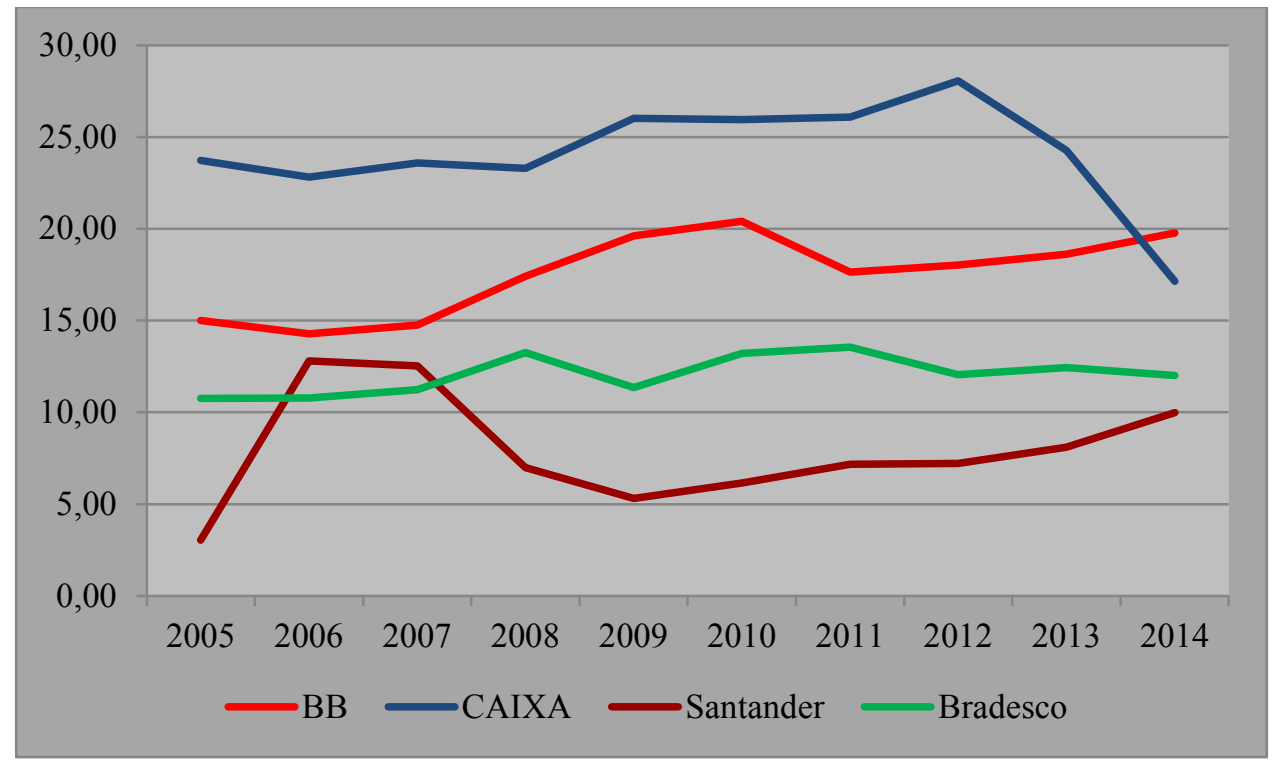

Fonte: Elaborado pelos autores a partir da CVM e da Caixa.

Gráfico 10 - Liquidez corrente do BB, Caixa, Bradesco e Santander entre 2005 e 2014

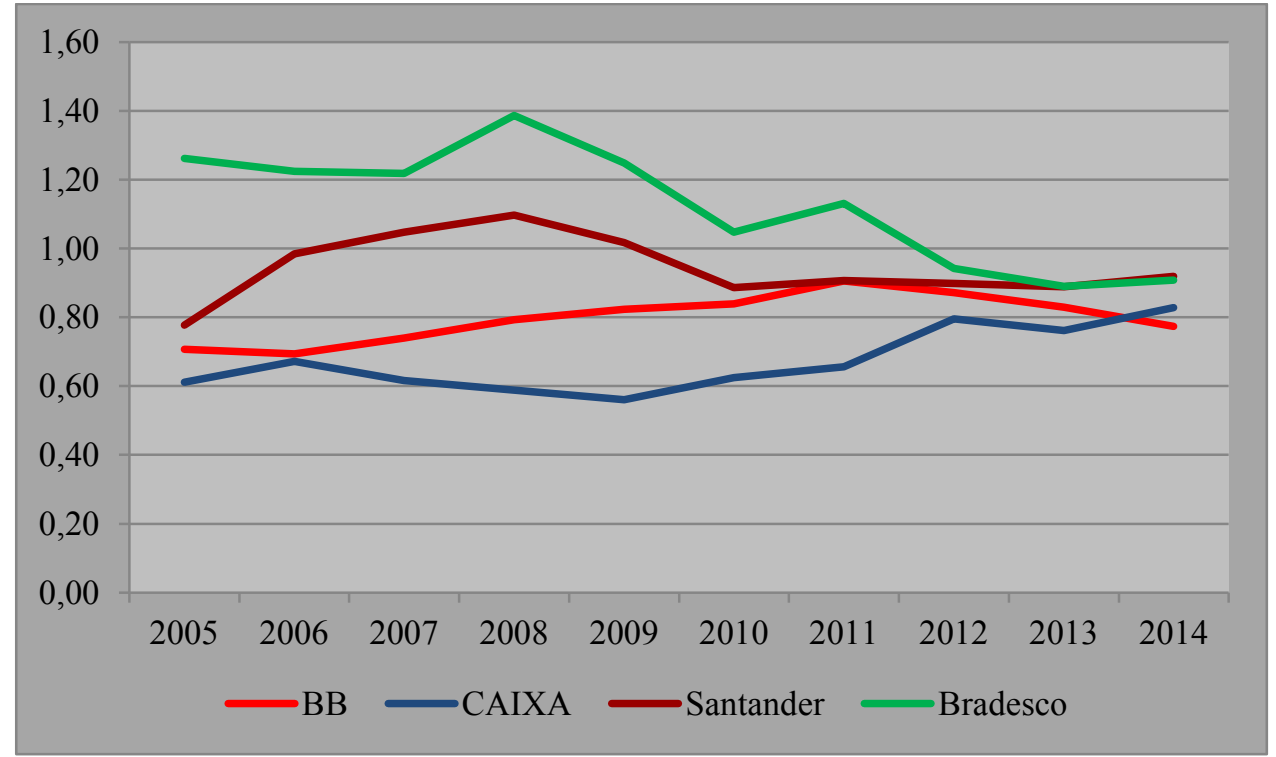

Fonte: Elaborado pelos autores a partir da CVM e da Caixa. 


\section{Text.}

http://dx.doi.org/10.5007/2175-8085.2018v21n2p26

\section{CONCLUSÃO}

O presente artigo realizou uma avaliação sucinta de dados de condições financeiras dos bancos públicos federais brasileiros, tomando como consideração dois indicadores financeiros típicos, um indicador de alavancagem financeira, e um de liquidez corrente, para verificar em que grau os três maiores bancos públicos do país, mesmo consideradas as suas diferenças institucionais, reagiram ao período de crise financeira que acometeu a economia mundial a partir de 2008. Buscou-se comparar, mesmo que de forma limitada, as diferenças entre essas instituições tanto entre si, quanto em relação a outras duas instituições bancárias privadas atuantes no mercado brasileiro. A análise revela que, em certo sentido, se pode afirmar que esses bancos públicos brasileiros efetivamente revelam ter assumido uma missão de atuação anticíclica, frente à crise financeira, ao se alavancarem mais e diminuírem, em termos relativos ao período pré-crise, seus indicadores de liquidez corrente.

Os resultados que surgem nas suas demonstrações contábeis, no exato momento em que as instituições privadas se retraíam das atividades de concessão de crédito, mostram que esses bancos atuaram em direção contrária ao comportamento típico das instituições bancárias privadas, ao longo do ciclo econômico. Enquanto a economia brasileira no pós-crise enfrentava problemas de empoçamento de liquidez, justamente porque o advento da crise faz elevar a incerteza estrutural da economia, levando o sistema financeiro e os bancos privados, em particular, a se tornarem menos propensos a assumir os riscos de concessão de crédito num cenário mais incerto, coube aos três grandes bancos públicos assumir posturas financeiras mais ousadas, no sentido de abrir canais de crédito e de provisão de liquidez na economia, atenuando o efeito de retração dos seus congêneres privados. Além disso, houve ainda, no caso dos dois maiores bancos comerciais públicos do país, o fato de ambos terem sido utilizados também para tentar promover uma política de redução das taxas de juros de operações de crédito no país.

A presente análise reforça um ponto teórico, amplamente defendido na perspectiva teórica pós-keynesiana: o de que os agentes privados manifestam tipicamente comportamentos pró-cíclicos, cabendo à política econômica as ações anticíclicas de natureza corretiva. No que diz respeito especificamente ao setor bancário na economia brasileira, enquanto os dois bancos privados utilizados como comparação na última parte da análise acima adotavam tipicamente posturas financeiras mais hedgers, no sentido de Minsky, no imediato pós-crise, os bancos públicos se tornaram mais arriscados, assumindo a 


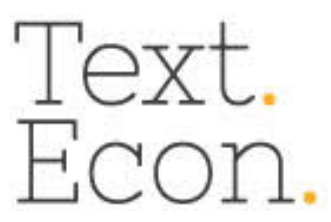

http://dx.doi.org/10.5007/2175-8085.2018v21n2p26

responsabilidade de suprir as lacunas deixadas pelo setor privado retraído, no processo de promoção de maior liquidez numa economia em geral assustada com os desdobramentos da crise financeira. $^{27}$

Em que pese uma série de questionamentos que são frequentemente colocados, sobretudo na imprensa e entre defensores do estado mínimo, a respeito da necessidade da existência de bancos públicos e, em especial, das condições das finanças dessas instituições, fica claro que um país em desenvolvimento não pode abrir mão de dispor de instrumentos de política anticíclica, incluindo aí bancos nos quais o governo tenha efetiva capacidade de orientar a atuação.

A crise econômica iniciada em 2008, que retraiu mercados de crédito em todo o mundo, foi enfrentada, no contexto brasileiro, entre outras medidas que fogem ao escopo desse trabalho, com uma explícita orientação anticíclica da atuação dos bancos públicos federais, isto é, das suas posturas em termos de concessão de crédito e provisão de meios de pagamento.

Embora não seja objetivo do artigo questionar a efetividade dessas políticas, o fato de que o instrumento da orientação das possíveis ações mitigadoras por parte dos bancos públicos existia e estava à disposição do governo, como parte de sua "caixa de ferramentas" anticíclicas - tendo sido efetivamente utilizado - é o que, na perspectiva do presente trabalho, deve ser destacado. Essa ação permitiu à economia brasileira apresentar, no que diz respeito à provisão de crédito, uma trajetória pós-crise menos traumática do que a observada em outros países. A resposta de tais instituições bancárias tenderia a ser completamente outra, muito mais pró-cíclica, caso fossem voltadas exclusivamente para gerar lucros, sem uma atuação estratégica mais voltada para o crescimento e o desenvolvimento econômico do país.

\section{REFERÊNCIAS BIBLIOGRÁFICAS}

ABRÃO, N. Direito Bancário. 12ª ed. São Paulo: Saraiva, 2009.

ADMATI, A. R.; HELLWIG, M. The Bankers New Clothes: What's wrong with banking and what to do about it. Princeton (NJ): Princeton University Press, 2013.

\footnotetext{
${ }^{27}$ É uma pergunta que vale a análise, não no escopo do presente trabalho, mas para investigações futuras, se este comportamento por parte dessas instituições públicas poderia ser chamado de "especulativo", no sentido utilizado por Minsky.
} 
ARAUJO, V. L.; CINTRA, M. A. M. O papel dos Bancos Públicos Federais na Economia Brasileira. Brasília: Ipea (Texto para Discussão nº 1.604). 2011.

BAIR, S. Bull by the Horns: Fighting to save Main Street form Wall Street and Wall Street form itself. New York: Free Press, 2012.

BIELSCHOWSKY, R. Pensamento Econômico Brasileiro: O ciclo ideológico do desenvolvimentismo. Rio de Janeiro: Contraponto, 2000, 480 p.

BLINDER, A. S. After the Music Stopped: The financial crisis, the response, and the work ahead. New York: The Penguim Press, 2013.

BNDES. Demonstrações Financeiras. Disponível em:

$<$ http://www.bndes.gov.br/wps/portal/site/home/relacoes-com-investidores/demonstracoesfinanceiras/demonstracoes-financeiras-bndes/>. Acesso em: 12 out. 2016.

BRASIL. Comissão proíbe privatização da Caixa Econômica Federal. 2016. Disponível em: $<\underline{\text { http://www2.camara.leg.br/camaranoticias/noticias/ADMINISTRACAO- }}$ PUBLICA/511597-COMISSAO-PROIBE-PRIVATIZACAO-DA-CAIXA-ECONOMICAFEDERAL.html>. Acesso em: 11 nov. 2016.

CARVALHO, F. J. C. Investimento, poupança e financiamento do desenvolvimento. In: SOBREIRA, R.; RUEDIGER, M. A. (Org.). Desenvolvimento e construção nacional: política econômica. Rio de Janeiro: FGV Editora, 2005. p. 11-37.

CARVALHO, F. J. C. Reformas financeiras para apoiar o desenvolvimento. In: IPEA. Macroeconomia para o desenvolvimento: crescimento, estabilidade e emprego. Brasília: IPEA, 2010, p. 309-32.

CARVALHO, F. J. C. Liquidity Preference and Monetary Economies. London and New York: Routledge, 2015.

CARVALHO, C.E; OLIVEIRA, G. C.; TEPASSÊ, A. C. A revelação da atuação dos bancos federais brasileiros diante dos impactos da Crise Financeira Internacional. In: Associação Keynesiana Brasileira. Dossiê da Crise II, 2010, p. 64-70.

CGFS (Committee on the Global Financial System). Global liquidity - concept, measurement and policy implications. Basel: BIS/CGFS (CGFS Papers n. 45), 2011.

CINTRA, M. A. M. Crédito público e Desenvolvimento Econômico: A experiência brasileira. In: FERREIRA, F. M. R.; MEIRELLES, B. B. (Org.). Ensaios sobre economia financeira. Rio de Janeiro: BNDES, 2009. p. 57-108.

CORDEIRO, B. F. A Crise Econômica de 2008 e a Atuação dos Bancos Públicos Brasileiros. 2015. Disponível em:

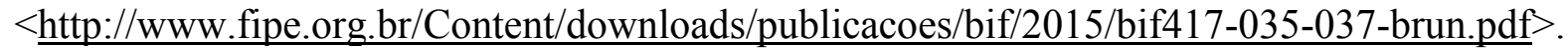
Acesso em: 19 jun. 2016. 


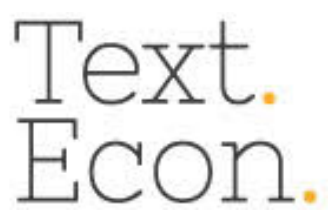

http://dx.doi.org/10.5007/2175-8085.2018v21n2p26

COUTINHO, L. A Crise Econômica Internacional: Recife: Conselho Estadual de Desenvolvimento Econômico e Social, 2009. Color.

COUTO, A. C. L.; TRINTIM, J. G. O Papel do BNDES no Financiamento da Economia Brasileira. In: Encontro Internacional da Associação Keynesiana Brasileira, 7., 2012, São Paulo. Anais... São Paulo: Associação Keynesiana Brasileira, 2012.

DE PAULA, L.F. Preferência pela Liquidez e a Natureza da "Crise” Brasileira. In.: Associação Keynesiana Brasileira. Dossiê da Crise. Novembro de 2008, p. 64-68.

FREITAS, M. C. P. Os Efeitos da Crise Global no Brasil: Aversão ao risco e preferência pela liquidez no mercado de crédito. Estudos Avançados, São Paulo, IEA/USP, v. 66, n. 23, p. 125-145, 2009.

GERSCHENKRON, A. Economic Backwardness in Historical Perspective: a book of essays. London: The Belknap Press of Harvard University Press, 1962.

GOODHART, C. A. E. The Regulatory Response to the Financial Crisis. Cheltenham (UK): Edward Elgar, 2009.

GURLEY, J; SHAW, E. Financial Aspects of Economic Development. American Economic Review, Vol. XLV, n. 4, p. 515-38, September, 1955.

HERMANN, J. Bancos públicos em Sistemas Financeiros Maduros: Perspectivas teóricas e desafios para os países em desenvolvimento. In: Encontro Internacional da Associação Keynesiana Brasileira, 2, Anais... Porto Alegre: UFRGS, 2009a.

HERMANN, J. Bancos de Desenvolvimento na "Era da Liberalização Financeira: O caso do BNDES nos anos 1990-2006. 2009b. Mimeo.

HERMANN, J. O Papel dos Bancos Públicos no Financiamento do Desenvolvimento Brasileiro. In: IPEA. Macroeconomia para o desenvolvimento: crescimento, estabilidade e emprego. Brasília: IPEA, 2010, p. 277-308.

KING, M. The End of Alchemy: Money, banking and future of the global economy. New York: Norton, 2016.

KREGEL, J. Minsky's Cushions of Safety: Systemic risk and the crisis in the U.S. subprime mortage market. Public Policy Brief, Highligts, $n^{\circ}$ 93A. The Levy Economics Institute of Bard College, 2008.

MENDONÇA, A. R. R.; DEOS, S. O Papel dos Bancos Públicos e a Experiência Brasileira Recente. In. Associação Keynesiana Brasileira. Dossiê da Crise II. 2010, p. 63-4.

MINISTÉRIO DA FAZENDA. Caixa Econômica Federal passa por reestruturação patrimonial. 2001. Disponível em:

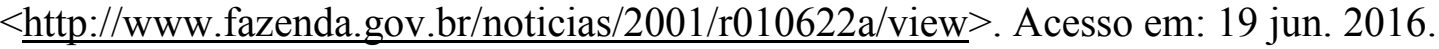




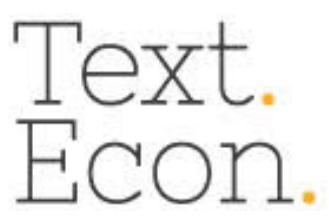

http://dx.doi.org/10.5007/2175-8085.2018v21n2p26

MINISTÉRIO DA FAZENDA. Fortalecimento das instituições financeiras federais. 2001. Disponível em: $<$ http://www.fazenda.gov.br/noticias/2001/r010622>. Acesso em: 19 jun. 2016.

MINSKY, H. P. (1975 [2010]). John Maynard Keynes. New York: Columbia University Press.

MINSKY, H. P. (1982). Can "It” Happen Again? Essays on instability and finance. Armonk/New York: M.E. Sharpe.

MINSKY, H. P. (1986 [2008]). Stabilizing an Unstable Economy. $2^{\text {nd }}$ ed. New York: McGraw-Hill, 2008.

OLIVEIRA, G. C. O Comportamento do Crédito e a Reação do Banco Central e do Sistema Financeiro Público e Privado aos Efeitos da Crise Internacional. In: Encontro Internacional da Associação Keynesiana Brasileira, 2., Anais..., Porto Alegre: UFRGS, 2009.

OREIRO, J. L.; BASÍLIO, F. A. C. A Crise Financeira Brasileira: Uma análise a partir do conceito de fragilidade financeira à la Minsky. In.: Associação Keynesiana Brasileira. Dossiê da Crise. Novembro de 2008, p. 59-63.

PAPADIMITRIOU, D. B.; WRAY, L. R. Introduction: Minsky on money, banking and finance. In: PAPADIMITRIOU, D.B.; WRAY, L. R. (eds.). The Elgar Companion to Hyman Minsky.

Cheltenhan, UK; Northampon (MA): Edward Elgar; 2010; pp. 1-30.

PASSOS, D. S. A Crise de 2008 e o Banco do Brasil: Um estudo de caso. 2010. 63 f. TCC (Graduação) - Curso de Economia, Universidade Federal do Rio Grande do Sul, Porto Alegre, 2010.

PEREIRA, E. Quebra do Lehman Brothers - Setembro de 2008. 2009. Disponível em: $<$ http://www.administradores.com.br/artigos/economia-e-financas/quebra-do-lehmanbrothers-setembro-de-2008/33932/>. Acesso em: 19 jun. 2016.

PINHEIRO, A. C.; OLIVEIRA FILHO, L.C. (org.). Mercado de Capitais e Bancos Públicos: Análise e experiências comparadas. Rio de Janeiro: Contra Capa, 2007.

REDIVO, A. S. Banco Público como Agente de Desenvolvimento: A atuação do BNDES no período recente - 1990/2011. Dissertação (Mestrado) - Programa de Pós-Graduação em Economia, Universidade Federal de Santa Catarina, Florianópolis, 2012.

SILVA, G. B. Caixas Econômicas: A questão da função social. Rio de Janeiro: Forense, 2004. 263 p.

SIQUEIRA, A. C. T. A História dos Bancos no Brasil: Das contas bancárias aos conglomerados financeiras. Rio do Janeiro: Cop, 2007. 344 p.

VASCONCELOS, D. S. Regulação Bancária, Liquidez e Crise Financeira: Uma análise da proposta de regulação de liquidez em Basileia III. Tese (Doutorado) - Instituto de Economia/Universidade Federal do Rio de Janeiro, Rio de Janeiro, 2014. 


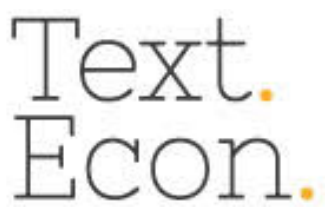

http://dx.doi.org/10.5007/2175-8085.2018v21n2p26

ZYSMAN, J. Governments, Markets and Growth. London: Cornell University Press, 1983. 